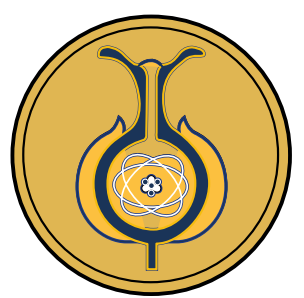

\title{
Aspectos del contexto socioambiental que inciden en la contaminación del recurso hídrico en un cantón urbano
}

\author{
Socio-environmental aspects affecting water contamination in an urban area \\ Aspectos do contexto socioambiental que incidem na contaminação hídrica \\ em uma área urbana
}

\begin{abstract}
Rolando Sánchez-Gutiérrez ${ }^{1}$, Carolina Alfaro-Chinchilla ${ }^{2}$, Kimberly Ledezma-Zamora ${ }^{1}$, Ligia Hernando-Echeverría ${ }^{3}$, Carmen Mora-Aparicio ${ }^{2}$, Roy Pérez-Salazar $^{2}$
\end{abstract}

Received: Nov/13/2020 • Accepted: Mar/19/2021 • Published: Jul/31/2021

\section{Resumen}

El objetivo fue identificar y analizar los aspectos más relevantes del contexto socioambiental de un cantón urbano, que inciden en la contaminación del recurso hídrico. Se realizó una investigación descriptiva con un enfoque mixto, en la cual, recopilando información primaria y secundaria, se lograron obtener datos relacionados con la percepción socioambiental en el cantón, los patrones de cambio en el uso de suelo, la identificación de fuentes potenciales de contaminación al recurso hídrico por vertidos y el estado actual de la gestión para las aguas residuales generadas en el cantón. Esto fue obtenido a través de un sondeo preliminar de percepción, verificación de información en campo, uso de imágenes satelitales, bases de datos de autoridades reguladoras, entre otras herramientas, con miras a, posteriormente, ser sistematizado y procesado para los análisis respectivos. Se observó que, en la población consultada, lo percibido en relación con el recurso hídrico es satisfactorio en términos de abastecimiento, no obstante, se evidenció desinterés con el manejo de las aguas residuales de los hogares. Para el uso del suelo, se notó un aumento en el área de uso urbano y una disminución en la zona boscosa, cambios que han incrementado en los últimos años. Además, fue posible identificar más de 230 fuentes potenciales de contaminación del recurso hídrico expresadas como vertidos directos o indirectos de aguas residuales. En cuanto a los vertidos regulados, los reportes operacionales evidenciaron un alto cumplimiento respecto a la normativa nacional, sin embargo, la carga orgánica neta vertida es alta. Las actividades comerciales y el crecimiento urbano del cantón inciden de manera negativa para acelerar los procesos de contaminación del recurso hídrico de la zona de estudio, por lo que se encuentran bajo una presión constante que debe manejarse a través de procesos participativos con enfoque de gestión integrada.

Rolando Sánchez-Gutiérrez, $\$ rolando.sanchez.gutirrez@una.ac.cr, (D) https://orcid.org/0000-0002-5050-021X

Carolina Alfaro-Chinchilla, $\triangle$ carolina.alfaro.chinchilla@una.cr, (D) https://orcid.org/0000-0002-3965-0540

Kimberly Ledezma-Zamora, \kmledezma@hotmail.es, (D) https://orcid.org/0000-0001-6551-4350

Ligia Hernando-Echeverría, \ ligia.hernando.echeverria@una.cr, (D https://orcid.org/0000-0001-7514-3661

Carmen Mora-Aparicio, $\triangle$ carmorapa@gmail.com, D https://orcid.org/0000-0002-4405-9480

Roy Pérez-Salazar, $\$ roy.perez.salazar@una.cr, (D) https://orcid.org/0000-0002-8137-8448

1 Escuela de Química, Laboratorio de Manejo del Recurso Hídrico y Grupo de Investigación en Isótopos Estables, Universidad Nacional, Heredia, Costa Rica.

2 Escuela de Química, Laboratorio de Gestión de Desechos, Universidad Nacional, Heredia, Costa Rica.

3 Escuela de Geografía, Laboratorio de Manejo de Cuencas, Universidad Nacional, Heredia, Costa Rica. 
Palabras clave: Percepción socioambiental; uso del suelo; actividades productivas; contaminación; recurso hídrico

\section{Abstract}

The purpose of the research was to identify and analyze the most relevant socio-environmental aspects causing contamination of water resources in an urban area. The study used descriptive research with a mixed approach, in which, through the collection of primary and secondary information, data was obtained related to socio-environmental perception, change patterns in land use, identification of potential sources of water contamination by discharge, and the current condition of wastewater management in the area. The information was obtained through a preliminary perception survey, field verification, satellite images, databases from regulatory authorities, and other sources. The surveyed population's perception regarding water supply is satisfactory; however, no interest was perceived regarding home wastewater management. The analysis of land use showed a progressive increase in the use of urban land and a decrease in the use of forest areas over the last years. In addition, over 230 potential sources of water contamination were found between direct and indirect discharges. Regarding regulated discharges, the operational reports showed compliance with national regulation, even though the net organic load was high. The commercial activities and urban development negatively affect the area and accelerate water pollution. Therefore, water bodies are under constant pressure, which must be managed using participatory processes with an integrated management approach.

Keywords: Socio-environmental perception; land use; productive activities; pollution; water resource

\section{Resumo}

A pesquisa teve como objetivo identificar e analisar os aspectos mais relevantes do contexto socioambiental em uma área urbana que incidem na contaminação hídrica. Foi realizada uma pesquisa descritiva com uma abordagem mista, da qual, ao coletar informações primárias e secundárias, foram obtidos dados relacionados com a percepção socioambiental no bairro, os padrões de mudança no uso de solo, a identificação de fontes potenciais de contaminação hídrica por descarga e 0 estado atual da gestão das águas residuais geradas nessa área. Esses dados foram adquiridos através de uma sondagem preliminar de percepção, verificação de informação em campo, uso de imagens satelitais, bases de dados de autoridades regulamentadoras, entre outras ferramentas, a favor de, posteriormente, ser sistematizados e processados para as respectivas análises. Observou-se que, na população consultada, o que foi percebido com relação ao recurso hídrico é satisfatório em termos de abastecimento, não obstante, ficou evidente o desinteresse com o manejo das águas residuais de suas casas. Com relação ao uso do solo, notou-se um aumento na área de uso urbano e uma diminuição na zona florestal, mudanças que vem crescendo nos últimos anos. Além disso, foi possível identificar mais de 230 fontes potenciais de contaminação hídrica retratadas como descargas diretas ou indiretas de águas residuais. No que diz respeito às descargas regulamentadas, os relatórios operacionais evidenciaram um alto cumprimento à normativa nacional, porém, a carga orgânica líquida descarregada é alta. As atividades comerciais e 0 crescimento urbano da área incidem, de maneira negativa, no aceleramento dos processos de contaminação hídrica da zona de estudo, estando, portanto, sob uma constante pressão de que deve ser manejada por meio de processos participativos com um enfoque de gestão integrada.

Palavras-chave: Percepção socioambiental; uso do solo; atividades produtivas; contaminação; recurso hídrico 


\section{Introducción}

El desarrollo urbano ha sido un tema de importante discusión para el desarrollo sostenible. Los núcleos poblacionales crecen cada día más y, por lo tanto, también aumentan los procesos urbanos de consumo y contaminación, por lo que se hace necesario un planeamiento inteligente e integrado del desarrollo que controle, en su origen, la fuente de diferentes problemas ambientales (Hernández-Moreno, Hernández-Moreno, \& Alcaraz-Vargas, 2018; McCormick et al., 2013).

Entre las principales causas de conflictos socio ambiental en las ciudades y los sitios urbanos, en general, se encuentran la contaminación del agua, la contaminación atmosférica, las actividades de consumo excesivas, las desigualdades sociales y la pobreza (Hidalgo-García, 2017). Para realizar un análisis global de los impactos de esta problemática, es necesario considerar, además, que la huella ecológica de las ciudades no permanece dentro de sus límites geográficos, sino que se extiende con el flujo de contaminación que produce (Verma \& Raghubanshi, 2018).

Las ciudades y sus gobiernos locales se enfrentan a grandes retos para poder alinear el crecimiento económico, y recuperar y proteger el ambiente local (McCormick et al., 2013). Por tanto, se hace necesario el compromiso con el desarrollo urbano sostenible, entendido como alcanzar un balance entre el desarrollo de la zona y la protección del ambiente, manteniendo ingresos, empleos, servicios e infraestructura social y de transporte (Hiremath et al., 2013).

En el marco de los objetivos de desarrollo sostenible, el objetivo 11 , referente a ciudades y comunidades sostenibles, menciona, como parte de sus metas para el año
2030, aumentar la urbanización inclusiva y sostenible, así como la capacidad de planificación y gestión participativa. En este sentido, los gobiernos locales cumplen un papel fundamental, dada su cercanía con las personas y el conocimiento de sus necesidades, lo cual resulta en una oportunidad de afrontar los desafíos ambientales globales a través de medidas locales (ICLEI, 2019).

Diferentes conceptos se han desarrollado en años recientes con el fin de poder analizar el flujo de materiales y emisiones en un modelo circular a nivel urbano. Para los sistemas de abastecimiento, uso y disposición de agua, el enfoque tradicional de operación y gestión, en la mayoría de los casos, no cumple con las aspiraciones de un servicio sostenible, por lo que es necesario promover el desarrollo de nuevas perspectivas que minimicen los impactos ambientales y propongan un costo adecuado. El crecimiento de la población en las zonas urbanas aumenta la demanda por el agua y para proveer de este recurso en forma satisfactoria, las instituciones que gestionan el servicio deben hacer uso de fuentes fuera del área urbana, situación que puede generar conflictos y competencia por el recurso (Mitchell, 2006). Por esta razón, desde el concepto de uso integrado del agua en el ciclo urbano, se establecen nuevos paradigmas como: 1) la consideración de los residuos como un recurso, 2) la valoración del agua de lluvia también como un recurso para la cosecha de agua o la infiltración, 3) la demanda multifacética del agua (los usos del agua definen la calidad requerida), 4) la reutilización múltiple del agua, desde usos de mayor calidad a los de menor calidad, 5) la infraestructura verde, basada en soluciones naturales como un complemento a la infraestructura hídrica gris y 6) los sistemas descentralizados como una opción (Mitchell, 2006; Mohammadkhani et al., 2021) 
El presente estudio tiene como objetivo analizar algunos aspectos del contexto social-ambiental en el cantón San Pablo, considerando los cambios en el uso del suelo, la identificación de fuentes potenciales de contaminación al recurso hídrico por vertidos, la situación actual de las aguas residuales generadas en este cantón y un sondeo preliminar de los principales aspectos socioambientales percibidos en el cantón.

\section{Metodología}

La investigación realizada es del tipo descriptiva con un enfoque mixto en la que se analiza la incidencia sobre la contaminación del recurso hídrico de aspectos relevantes de la condición socioambiental del cantón. A continuación, se describen los principales componentes metodológicos de esta investigación.

\section{Identificación de los principales as- pectos socioambientales percibidos en el cantón}

Se realizó un sondeo exploratorio, no paramétrico, sobre aspectos relacionados con la gestión del recurso hídrico, mediante la herramienta KoBoToolbox de libre acceso. El instrumento fue aplicado tanto en forma personal, por medio de visitas a hogares, así como también por medios digitales, mediante la divulgación a través de las redes sociales de la municipalidad del cantón. Posteriormente, se sistematizó y analizó la información recopilada para identificar aspectos importantes que deben abordarse con mayor profundidad en estudios posteriores.
Uso del suelo e identificación de fuentes potenciales de contaminación del recurso hídrico expresadas como vertidos de aguas residuales

El área de estudio corresponde al cantón San Pablo de la provincia de Heredia, Costa Rica. Este se ubica dentro de la microcuenca del río Bermúdez, la cual cubre una extensión de $33.35 \mathrm{~km}^{2} \mathrm{y}$, debido al crecimiento poblacional, ha presentado cambios en el uso del suelo a lo largo del tiempo. Para este estudio se realizó una comparación, desde el punto de vista geográfico, del uso del suelo para los años 2000, 2015, 2018 y 2019, mediante la generación de los mapas correspondientes.

Para los años 2000, 2015 y 2018 se utilizaron imágenes Landsat como base y se procesaron mediante el sistema de información geográfica (SIG) Arc Gis 10.2. En el 2019 se actualizó el mapa de uso mediante el análisis de imágenes RapidEye, utilizando el mismo SIG para su procesamiento. Lo anterior sirve de base para el análisis comparativo del comportamiento del cambio del uso del suelo, fundamental para el análisis de la relación entre las actividades productivas y otros aspectos ambientales del cantón.

Para las fuentes potenciales de contaminación al recurso hídrico expresadas como vertidos de aguas residuales provenientes de las actividades productivas, se utilizó la información de 713 patentes comerciales registradas en la Municipalidad de San Pablo, la ubicación de estas se verificó en campo mediante el uso de GPS (Garmin GPS Map 64sx) y con la aplicación de Google Maps. Esta información fue categorizada en dos grupos, primeramente, aquellas actividades que poseen plantas de tratamiento con permiso sanitario aprobado para el vertido fueron agrupadas como fuentes puntuales de contaminación (directa); mientras que las 
restantes actividades comerciales, al generar aguas residuales, pero sin vertido directo al cuerpo receptor, se categorizaron como fuentes indirectas de contaminación. Estas últimas se priorizaron según el potencial de generación de aguas residuales con metales pesados, grasas y aceites, lubricantes, fenoles, cargas altas de materia orgánica, nitrógeno o fósforo, entre otros.

\section{Aguas residuales vertidas en cuer- pos receptores}

Se analizaron 135 reportes operacionales de plantas de tratamiento de agua residual (2014-2018), para determinar el comportamiento de los parámetros de control obligatorio (caudal, temperatura, $\mathrm{pH}$, solidos sedimentables, (S.Sed), sólidos suspendidos totales (SST), grasas y aceites (GyA), sustancias activas al azul de metileno (SAAM), demanda bioquímica de oxígeno (DBO) y demanda química de oxígeno (DQO), establecidos en Reglamento de Vertido y Reúso de Aguas Residuales (RVRAR) (La Gaceta, 2007). Esta información se obtuvo a través de consulta al área rectora de salud del cantón San Pablo. Con la información colectada, se calculó la estadística descriptiva para todos los parámetros reportados; en el caso de los parámetros con valores menores a los límites de cuantificación (DBO, DQO GyA, SSed, SST y SAAM), se aplicó la técnica no paramétrica de estimación en datos incompletos de Kaplan Meier (1958). Las diferencias para los parámetros de control obligatorio de acuerdo con los sitios de vertido $\mathrm{y}$ actividades productoras fueron analizadas mediante técnicas de estadística inferencial no paramétrica como las permutaciones (Blair et al., 1994; Good, 2000) y la prueba Peto-Prentice (Peto y Peto, 1972; Prentice, 1978) en el caso de datos con valores menores al límite de cuantificación.
Adicionalmente, se realizó una estimación de la carga orgánica vertida expresada en términos de kg DQO/día, con el objetivo de generar un indicador relacionado a la generación de aguas residuales en sistemas de tratamiento, se analizó este indicador por sitio de vertido y actividad generadora.

\section{Análisis y resultados}

\section{Descripción del tipo de población y resultados del sondeo}

El cantón San Pablo cuenta con un área de $7.53 \mathrm{~km}^{2}$ y una población que supera los 30000 habitantes con un porcentaje de alfabetización de un $99.1 \%$. En cuanto al recurso hídrico, están presentes los ríos Bermúdez, Pirro, Quebrada Gertrudis y San Pablo. (Municipalidad de San Pablo, 2014).

Al ser el estudio realizado un sondeo de percepción, no se pueden generalizar los datos al total de la población; sin embargo, se lograron identificar aspectos clave que deben ser abordados en los procesos posteriores de gestión ambiental del cantón.

La población analizada consistió en un total de 40 personas (92\% costarricenses), la mayoría ( $75 \%$ ) vive hace más de 10 años tanto en el cantón como en la vivienda habitada actualmente, y la cantidad de personas por vivienda es de 2 a 4 personas principalmente (73\%).

Dentro de los aspectos principales a destacar se observó un conocimiento generalizado sobre quién es el proveedor del servicio de agua, pero no así del lugar de donde viene el recurso. También se observó una satisfacción alta en cuanto al servicio de abastecimiento (medido en las dimensiones de calidad, cantidad y continuidad).

No obstante, un servicio de calidad en términos del abastecimiento de agua 
implica mantener y operar los servicios de saneamiento en forma adecuada. La Organización Mundial de la Salud (2021, párr. 1) define el saneamiento como "el suministro de instalaciones y servicios que permiten eliminar sin riesgo la orina y las heces". Desde el abordaje de la salud pública, el mantener condiciones adecuadas de saneamiento favorece la salud de las personas y los ecosistemas.

En Costa Rica, la principal solución de saneamiento consiste en tanques sépticos. Se estima para al año 2015 que el 76.43 $\%$ de las viviendas del país contaba con un tanque séptico como opción de saneamiento, mientras que solamente el $21.43 \%$ tenía conexión a sistema de alcantarillado, del cual solamente una parte poseía planta de tratamiento. (Ministerio de Salud, MINAE, AyA, 2016). Esta tendencia en el uso de tanques sépticos también se observó en el cantón, donde las personas consultadas mencionaron que están construidos de diferentes materiales como plástico y concreto $\mathrm{y}$, en algunos casos, incluso, no se conoce el tipo de material.

Los tanques sépticos consisten en un sistema biológico que trata el agua mediante procesos de sedimentación de los sólidos, y una posterior infiltración en el suelo del efluente del proceso de sedimentación primaria. La acumulación de lodos en el tanque primario requiere de una remoción manual periódica para evitar el paso de estos a la zona de infiltración. La periodicidad de la remoción, conocida como el periodo de diseño, depende del volumen dimensionado del tanque, de acuerdo con la cantidad de personas que lo utilizan (Rosales-Escalante, 2016). Normalmente este valor no es conocido por los usuarios, y por lo tanto la remoción de los lodos se hace cuando visualmente se observa un nivel de lodos en el tanque cercano a su salida o, lo que es más grave, cuando se da un rebalse de las aguas, especialmente en época lluviosa. Dentro de la muestra de personas consultadas, se observaron dos situaciones: tanques llevan más de 5 años sin hacer extracción de lodos, lo que podría implicar un inadecuado nivel de tratamiento con su consecuente contaminación del suelo y el agua subterránea, y tanques que tienen más de 10 años de construidos y podrían requerir de mantenimiento para asegurar un funcionamiento correcto.

El agua tratada en los tanques sépticos puede ser tanto la generada en los servicios sanitarios (conocidas como aguas negras) o las generadas en las duchas, lavamanos, actividades de lavado de ropa y limpieza, entre otras (conocidas como aguas grises). Aunque ambas se pueden tratar en estos sistemas, es una práctica común que solamente se traten las aguas negras, para alargar el periodo de limpieza explicado anteriormente. La Figura 2 presenta el destino de las aguas residuales para la población consultada. Se observó que, en algunos casos, aunque las aguas negras son enviadas al tanque séptico, no sucede lo mismo con las aguas grises, e incluso algunas personas mencionaron que envían las aguas al alcantarillado, a pesar de que no existe alcantarillado sanitario en la zona, lo que evidencia la confusión entre los conceptos de alcantarillado sanitario y alcantarillado pluvial y la contaminación potencial de las aguas grises que no son tratadas.

Con el fin de analizar la apertura de la población a mejorar las condiciones de saneamiento, y considerando los proyectos de mejoramiento ambiental en saneamiento que se pretende desarrollar para este cantón, se consultó sobre la disponibilidad a pagar un monto adicional en su factura del servicio de agua destinado al saneamiento, así como la disponibilidad a conectarse al sistema de 


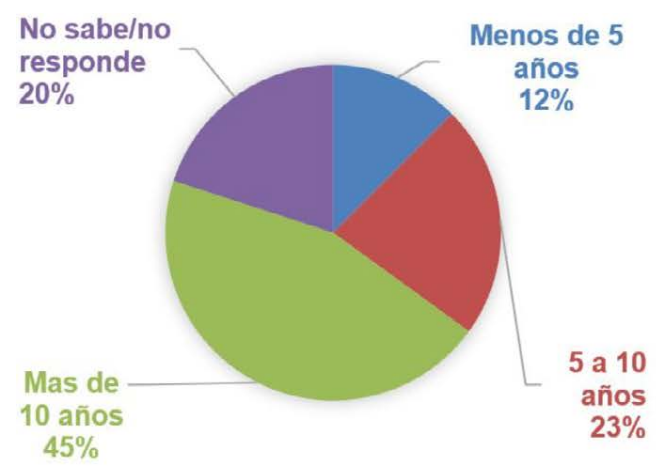

(a) Años desde la construcción del tanque séptico

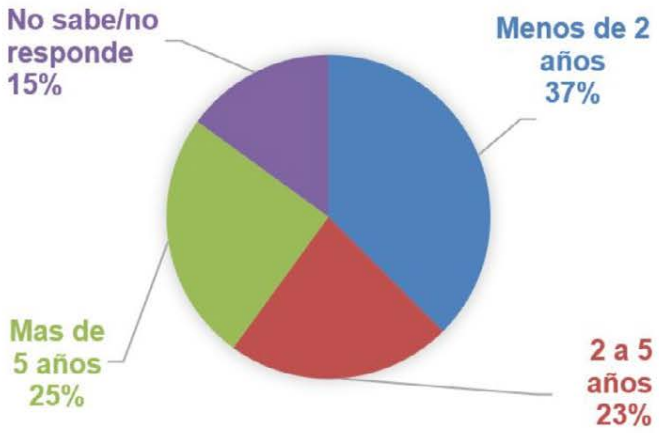

(b) Años transcurridos desde la última limpieza de lodos del tanque séptico

Figura 1. Características de los tanques sépticos.

Nota: Fuente propia de la investigación.

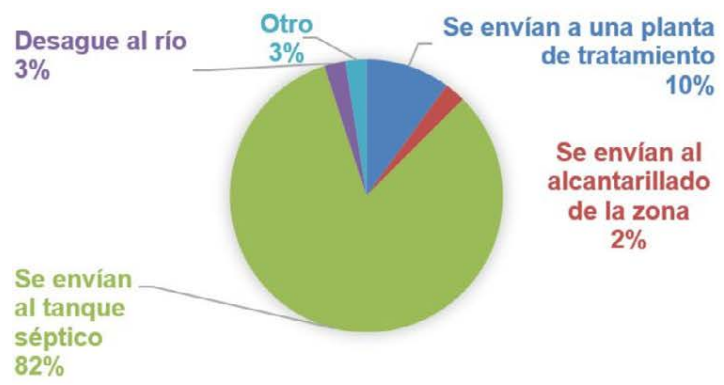

(a) Destino de las aguas negras generadas en la vivienda

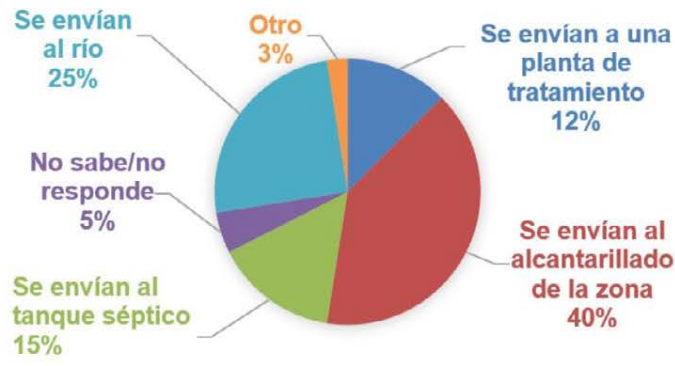

(b) Destino de las aguas grises generadas en la vivienda

Figura 2. Destino de las aguas residuales generadas en las viviendas.

Nota: Fuente propia de la investigación.

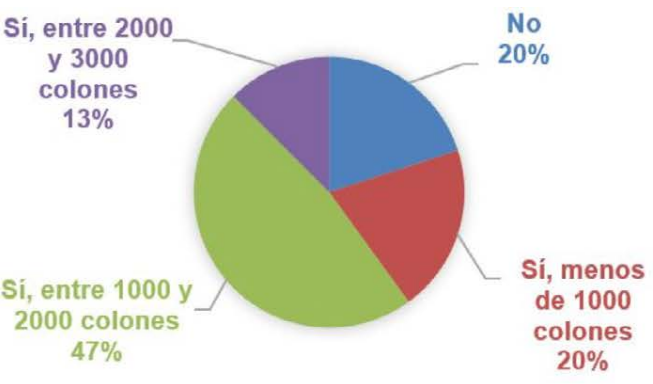

(a) Disponibilidad para pagar por un servicio de saneamiento

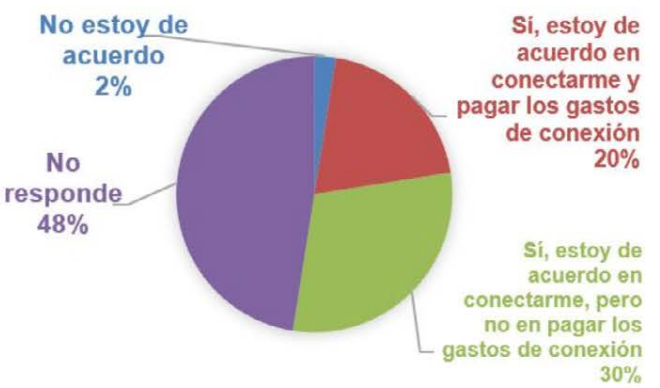

(b) Disponibilidad para conectarse a un sistema de alcantarillado sanitario

Figura 3. Disponibilidad para pagar y conectarse a un sistema de alcantarillado y saneamiento. Nota: Fuente propia de la investigación.

alcantarillado sanitario en caso de que algún proyecto se concretara. Según se observa en la Figura 3, hay una disposición general a pagar por el servicio de saneamiento, aunque hay una disposición menor a pagar por la conexión al servicio de alcantarillado. Este es uno de los aspectos que requieren de sensibilización en la población, para una adecuada implementación, a futuro, del sistema de alcantarillado sanitario. 
En cuanto a la percepción del entorno, algunas personas mencionaron no conocer cuál es el río cercano a su vivienda, situación que refleja poca identidad ambiental local en este grupo de personas; mientras que algunas mencionaron que no es agradable vivir cerca de un río, lo que puede relacionarse con la calidad de los ríos cercanos, algunos de ellos con problemas de contaminación importantes.

La gestión de los residuos sólidos influye directamente en la calidad de los cuerpos de agua, pues su disposición inadecuada puede generar procesos de contaminación del suelo, aguas superficiales, subterráneas y puede, además, originar problemas de salud e impactos en la calidad de los paisajes y la biodiversidad (Castillo y Saénz., 2020). La mayoría de las personas consultadas indicaron que hacen la disposición de los residuos mediante un servicio de recolección particular o público, y también realizan separación de residuos reciclables en sus hogares.

\section{Cambios en el uso de suelo}

Los cambios en los usos de suelo en cuencas altamente urbanizadas han sido identificados como factores importantes que pueden influenciar directamente en la contaminación del recuro hídrico ( $\mathrm{Li}, \mathrm{Li}$ y Kong, 2020). La microcuenca del río Bermúdez, durante las dos últimas décadas, ha experimentado cambios en el uso de suelo bastante significativos (Fig. 4). Durante el año 2000 , el pasto es el uso que predomina a lo largo de la microcuenca, con un $35 \%$ del área. Al norte y este de la microcuenca prevalece el bosque de baja densidad con un $28 \%$, y al extremo norte se ubica el bosque de alta densidad, cubriendo un $4 \%$ del área. El uso urbano se encuentra como áreas aisladas especialmente en la cuenca media y baja, sector donde se ubica el cantón San
Pablo, el segundo uso de mayor cobertura con un $33 \%$. Para el año 2015, la cobertura boscosa se reduce en un $3 \%$ y el bosque de ribera apenas ocupa un $6 \%$ de cobertura en la microcuenca. Por otra parte, el uso urbano incrementó sustancialmente, ya que para este año ocupa el $49 \%$ del área mientras que el pasto se redujo a un $13 \%$.

Para el año 2018, se registra el uso de cultivo de café, que equivale a un $43 \%$ del área de la microcuenca. Este uso toma el lugar de sectores cubiertos de bosque hacia el este de la microcuenca, el cual disminuye a un $4 \%$. Respecto a las áreas cubiertas por pasto, para el 2018 aumentan con respecto al 2015 y cubren un $17 \%$ del área de estudio. El uso urbano, disminuye, al igual que el bosque de ribera; el primero abarca un 34 $\%$ y el segundo un $2 \%$; ambos usos sustituidos por el cultivo de café. Finalmente, en el 2019, el uso urbano aumenta y vuelve a cubrir el $49 \%$ de la microcuenca, siendo el uso con mayor extensión y principalmente ubicado en el cantón San Pablo. Este aumento urbano provoca la disminución del café y pasto con una extensión de $33 \%$ y 9 $\%$ del área total, respectivamente. Por otra parte, hacia el suroeste de la microcuenca, el uso de café o de bosque de ribera pasa a ser terreno descubierto, con una extensión de $3 \%$. El bosque, por su parte, disminuye y cubre el $5 \%$ de la microcuenca.

En términos generales se puede indicar que el cambio total del uso de suelo consistió en una disminución de un $27 \%$ de la cobertura boscosa y $26 \%$ de pastos con un aumento para las coberturas urbana (16\%), de cultivo de café (33\%) y de terreno descubierto ( $3 \%$ ), estos tres últimos usos caracterizados por tener impactos negativos sobre la calidad del recurso hídrico, pues pueden comportarse como fuentes de contaminación no puntuales, debido a las 

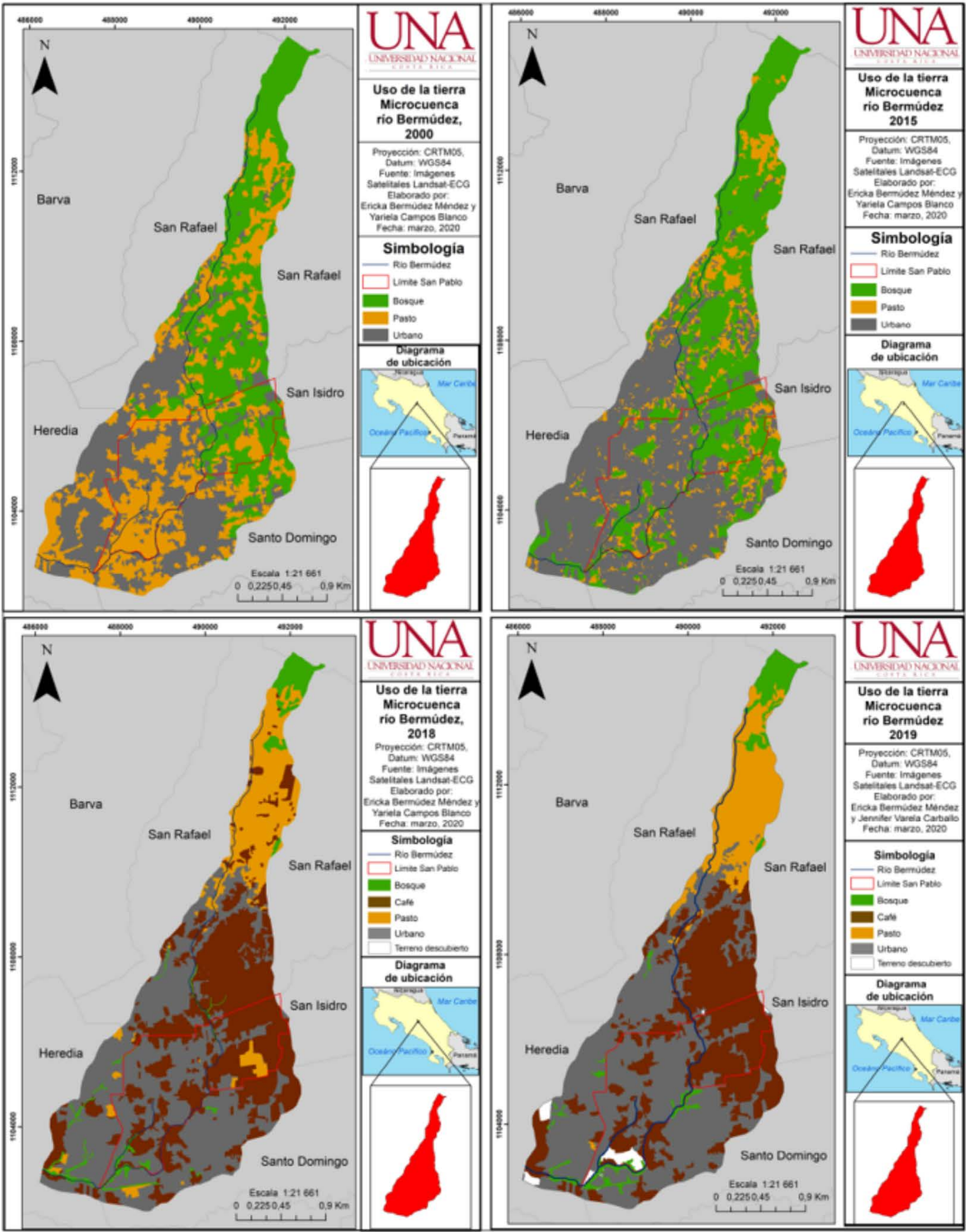

Figura 4. Comparación del uso de suelo en el cantón San Pablo en el periodo comprendido entre el 2000 y 2019. Fuente propia de la investigación.

Nota: Fuentes potenciales de contaminación al recurso hídrico por vertidos 
actividades comerciales, productivas y de vivienda que en estos se desarrollan, así como las consecuencias ocasionadas por efectos de impermeabilización y escorrentía de los suelos (de Mello et al., 2020; Song, Song, Shao y Hu, 2020). Así mismo, estudios han demostrado una relación entre aumento de contaminación del agua superficial con respecto al aumento de poblacional (Barrenha et al., 2018; Calvo-Brenes \& Mora-Molina, 2012).

En Costa Rica, las plantas de tratamiento de aguas residuales de diversas actividades productivas, consideradas como fuentes puntuales de contaminación al recurso hídrico, vierten gran cantidad de carga orgánica a cuerpos receptores en áreas altamente urbanizadas cercanas a la zona de estudio (Mena-Rivera et al., 2017; Sánchez-Gutiérrez y Gómez-Castro; 2021). En la Figura 5, se muestran más de 18 fuentes de estos vertidos identificados en el cantón, provenientes de diversas actividades productivas. Más adelante se profundizará el análisis de las cargas vertidas por estas fuentes, en aras de verificar su cumplimiento regulatorio y obtener un indicador que permita conocer la carga diaria que se dispone en el cantón.

También, en la Figura 5, se muestran las fuentes indirectas de contaminación. Estas corresponden a las actividades comerciales que, por la naturaleza de su proceso, poseen mayor probabilidad de generar aguas residuales con mayor impacto potencial de contaminación. Representan un 27 \% (más de 193 actividades) del total de patentes comerciales del cantón, dentro de las cuales se consideran actividades como sodas, restaurantes, talleres mecánicos, salas de estética, entre otras. Las aguas residuales generadas

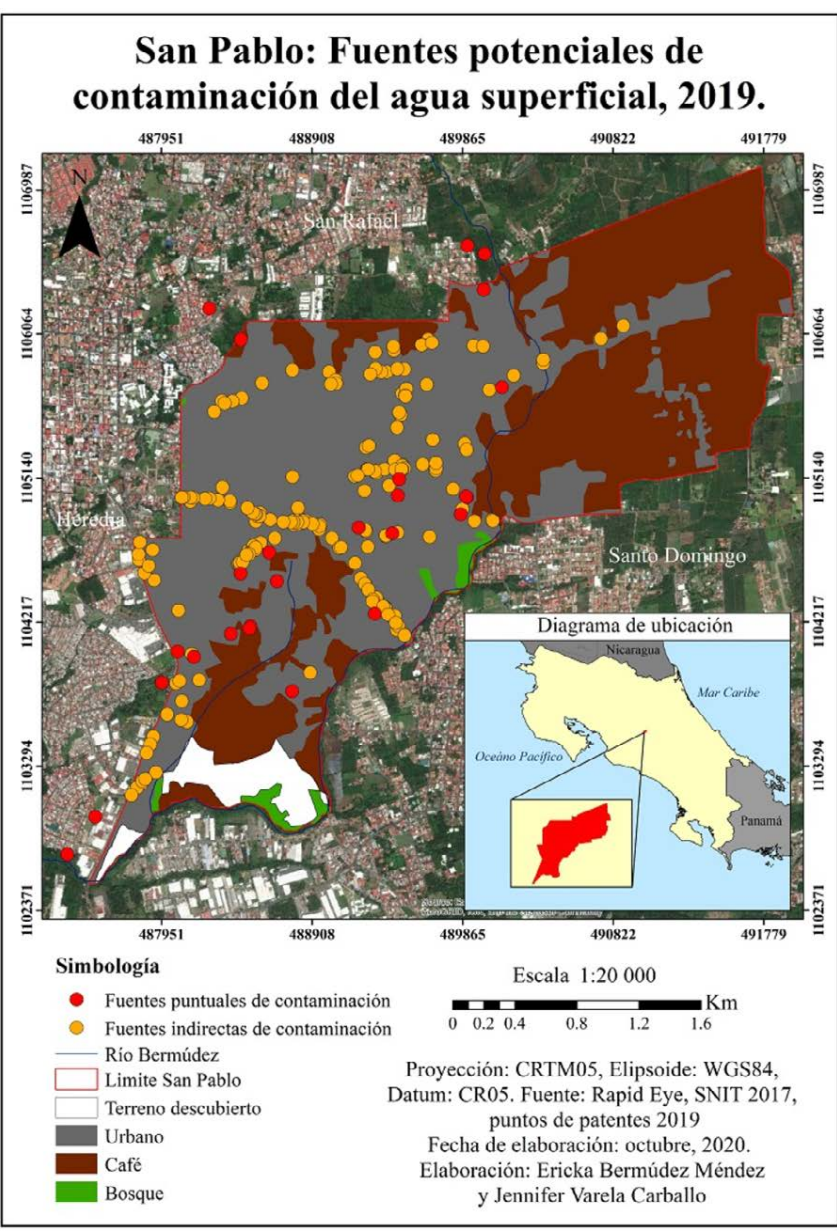

Figura 5. Principales actividades productivas en el cantón San Pablo.

Nota: Fuente propia de la investigación.

por estas actividades aportan gran cantidad de sustancias como fosfatos, nitratos, fertilizantes, pesticidas, metales pesados y altas cargas orgánicas (Brenes, 2007; Calvo-Brenes \& Mora-Molina, 2012), en el área de estudio se observó que estas son directamente vertidas al sistema de alcantarillado; no obstante, actualmente no reciben tratamiento y, por ende, el sumidero final son los cuerpos receptores del cantón. Por tanto, con base en resultados obtenidos en otros estudios, es posible sugerir que son las fuentes indirectas las principales responsables de la degradación del recurso hídrico (Gomes y Wai, 2020). 
Los cuerpos de agua con altas cargas orgánicas pueden tener problemas por eutrofización y deficiencia de oxígeno, esto incide directamente en las características ecosistémicas y biofísicas del medio. Adicional a lo anterior, las descargas de fuentes directas y no directas ponen en riesgo la salud de las personas, ya que estas se relacionan con enfermedades como gastroenteritis, diarrea, brotes de mosquitos trasmisores de enfermedades, entre otros; además, limitan la cantidad de agua disponible para las distintas actividades (Naidoo \& Olaniran, 2013; Okoh et al., 2010; Wakelin et al., 2008), por lo que es necesario realizar un análisis de la capacidad de depuración del recuso de la zona, además de enfocar las medidas en mejorar el tratamiento de las aguas residuales y la implementación de sistemas eficientes de drenaje y alcantarillado (Mena-Rivera et al., 2018)

\section{Análisis de vertidos de aguas residuales}

Las concentraciones de los parámetros de control obligatorio para las plantas de tratamiento de agua residual ubicadas en el cantón San Pablo se encuentran resumidas en la Tabla 1 y la Figura 6. Los valores de caudal (Fig 6.a) oscilan entre $0.03-285 \mathrm{~m}^{3} / \mathrm{día}$, esta distribución presenta diferencia significativa $(\mathrm{F}=14.7$, $\mathrm{p}<0.05)$ de acuerdo con el tipo de vertido realizado, donde se evidencia que el caudal en

Tabla 1. Resumen de las características fisicas y químicas para los vertidos de aguas residuales generados por PTAR's en el cantón San Pablo de acuerdo con el tipo de vertido realizado

\begin{tabular}{|c|c|c|c|c|c|c|}
\hline Parámetro & Unidades & Promedio & DE & Mínimo & Máximo & Límite máximo permisible ${ }^{3}$ \\
\hline \multicolumn{7}{|c|}{ Vertido en alcantarillado $(n=48)$} \\
\hline Caudal & $\mathrm{m}^{3} /$ día & 5.1 & 5.8 & 0.03 & 24.8 & No aplica \\
\hline Temperatura & ${ }^{\circ} \mathrm{C}$ & 24.0 & 3.7 & 7.4 & 31.5 & $15.0-40.0$ \\
\hline $\mathrm{pH}$ & - & 6.82 & 0.58 & 4.50 & 8.10 & $6.0-9.0$ \\
\hline $\mathrm{DBO}^{1}(\mathrm{n}=6)^{2}$ & $\mathrm{mg} / \mathrm{L}$ & 33.6 & 37.6 & $<0.1$ & 139.0 & 300 \\
\hline $\mathrm{DQO}^{1}(\mathrm{n}=5)^{2}$ & $\mathrm{mg} / \mathrm{L}$ & 73.7 & 80.6 & $<3.0$ & 374.0 & 750 \\
\hline $\operatorname{SST}^{1}(\mathrm{n}=11)^{2}$ & $\mathrm{mg} / \mathrm{L}$ & 22.4 & 24.6 & $<0.2$ & 116.0 & 300 \\
\hline S. Sed ${ }^{1}(n=27)^{2}$ & $\mathrm{~mL} / \mathrm{L}$ & 0.52 & 1.06 & $<0.1$ & 5.0 & 5 \\
\hline $\operatorname{GyA}^{1}(n=23)^{2}$ & $\mathrm{mg} / \mathrm{L}$ & 5.4 & 6.6 & $<0.2$ & 28.0 & 50 \\
\hline $\operatorname{SAAM}^{1}(\mathrm{n}=8)^{2}$ & $\mathrm{mg} / \mathrm{L}$ & 1.25 & 2.50 & $<0.10$ & 12.1 & 5 \\
\hline \multicolumn{7}{|c|}{ Vertido en cuerpo receptor $(n=87)$} \\
\hline Caudal & $\mathrm{m}^{3} /$ día & 42.0 & 66.4 & 0.09 & 285.0 & No aplica \\
\hline Temperatura & ${ }^{\circ} \mathrm{C}$ & 25.7 & 2.3 & 17.0 & 29.8 & $15.0-40.0$ \\
\hline $\mathrm{pH}$ & - & 6.91 & 0.93 & 2.50 & 8.43 & $5.0-9.0$ \\
\hline $\mathrm{DBO}^{1}(\mathrm{n}=4)^{2}$ & $\mathrm{mg} / \mathrm{L}$ & 16.7 & 12.2 & $<2.0$ & 48.0 & 50 \\
\hline $\mathrm{DQO}^{1}(\mathrm{n}=1)^{2}$ & $\mathrm{mg} / \mathrm{L}$ & 45.8 & 29.6 & $<0.4$ & 143.0 & 150 \\
\hline $\operatorname{SST}^{1}(\mathrm{n}=15)^{2}$ & $\mathrm{mg} / \mathrm{L}$ & 24.1 & 25.9 & $<0.2$ & 181.0 & 150 \\
\hline S. Sed $(n=48)^{2}$ & $\mathrm{~mL} / \mathrm{L}$ & 0.14 & 0.66 & $<0.1$ & 6.0 & 1 \\
\hline $\operatorname{GyA}^{1}(\mathrm{n}=30)^{2}$ & $\mathrm{mg} / \mathrm{L}$ & 5.6 & 11.2 & $<0.3$ & 102.0 & 30 \\
\hline $\operatorname{SAAM}^{1}(\mathrm{n}=29)^{2}$ & $\mathrm{mg} / \mathrm{L}$ & 0.43 & 0.65 & $<0.002$ & 5.0 & 5 \\
\hline
\end{tabular}

Notas: Elaboración propia. Con datos recopilados en el estudio a través de la autoridad reguladora (Ministerio de Salud, 2019). ${ }^{1}$ estimaciones del promedio y DE usando el método Kaplan-Meier; ${ }^{2}$ número de valores con datos menor al límite de cuantificación; DE, desviación estándar. 
a)

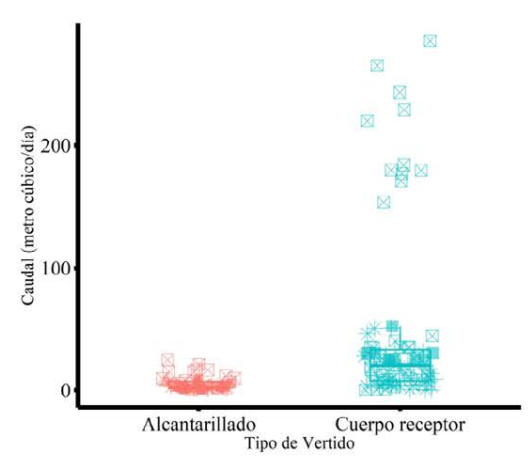

d)

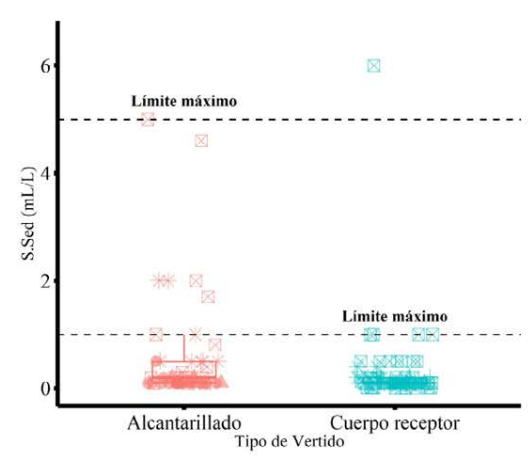

g)

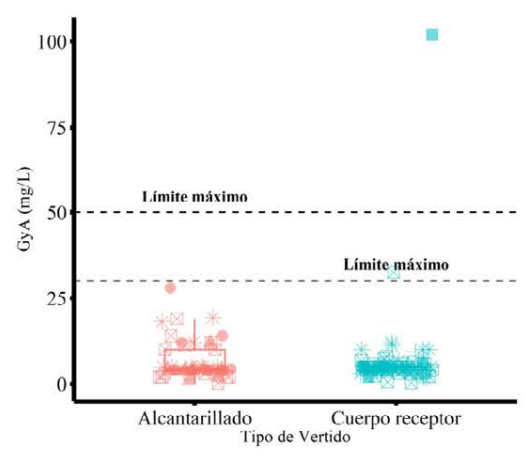

b)

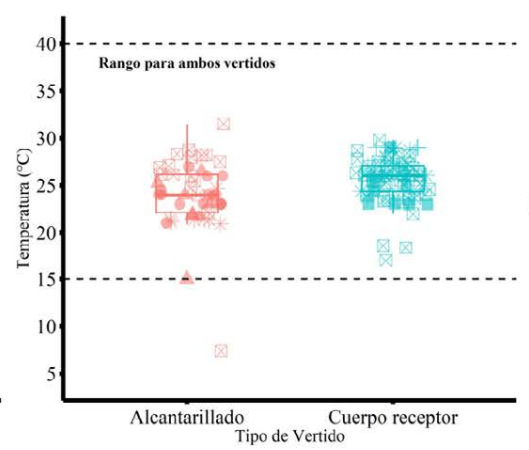

e)

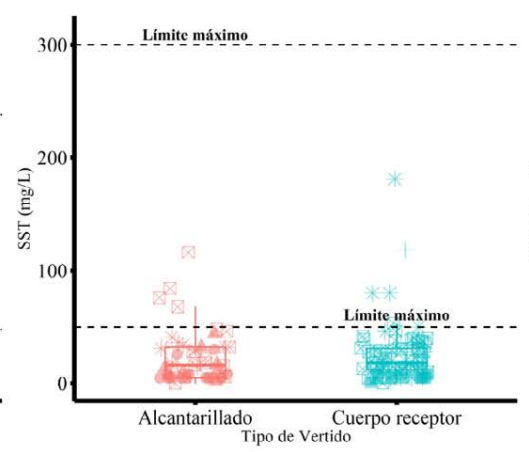

h)

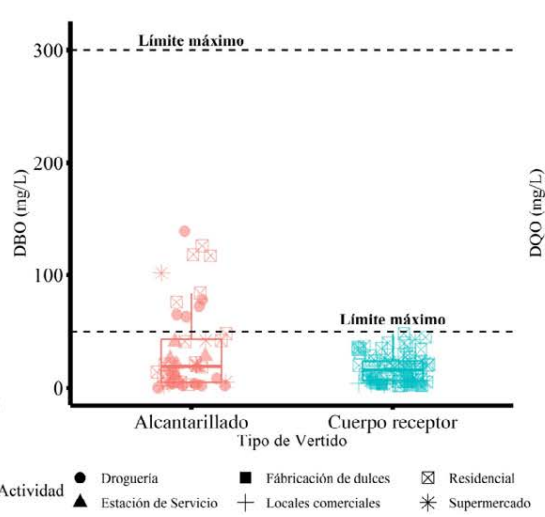

c)

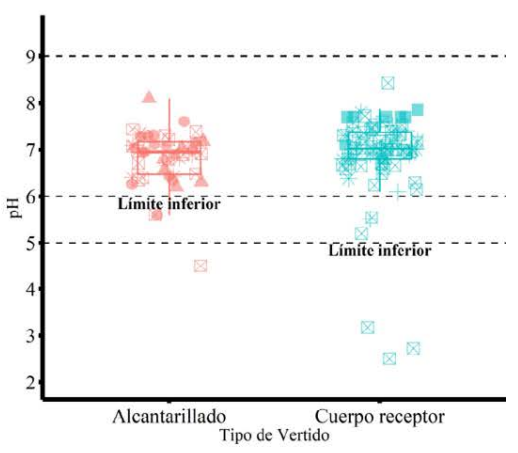

f)

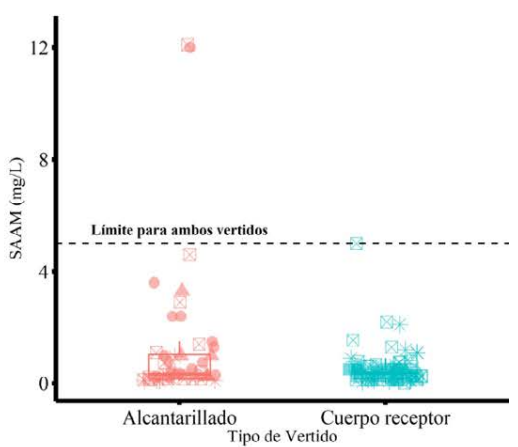

i)

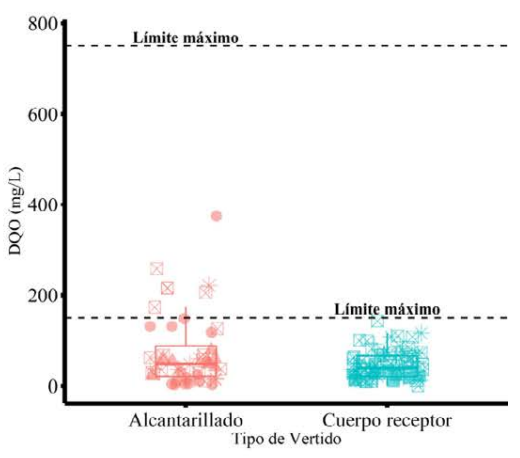

Figura 6. Variación de los parámetros de control obligatorio de los reportes operacionales de agua residual según tipo de vertido y actividad generadora.

Nota: propia de la investigación.

los cuerpos receptores es más de 8 veces la cantidad que se vierte al alcantarillado, y son los vertidos del sector residencial los que más contribuyen en esta diferencia. Lo anterior sugiere que el cantón San Pablo es densamente poblado (Hernando y Orozco, 2015) y que, independientemente del cumplimiento de los vertidos en relación con los límites máximos para cada variable de control, estos efluentes pueden contribuir, de forma significativa, a la afectación de diversas funciones ambientales, incluyendo, pero no limitándose a funciones de aprovisionamiento para actividades agrícolas de la zona (Sánchez-Gutiérrez y Villalobos-González, 2020). 
La temperatura de los efluentes oscila entre $7.42-31.5^{\circ} \mathrm{C}$ (Fig 6.b), con valores promedio muy similares en ambos tipos de vertido, además, se encontró solo un valor fuera del rango máximo admitido por el RVRAR; la variable $\mathrm{pH}$, osciló entre 2.508.43 (Fig 6.c), registrando casos de incumplimiento para el límite máximo inferior del RVRAR para ambos tipos de vertidos, incluidas las actividades del sector residencial, locales comerciales y droguería. Lo anterior puede estar relacionado con condiciones de anoxia en dichos vertidos, pues la degradación de materia orgánica en estas condiciones favorece procesos ácido génicos (Meegoda et al, 2018).

Los S.Sed oscilaron entre $<0.1-6.0$ mg/L (Fig 6.d), específicamente, los efluentes dispuestos en el alcantarillado sanitario mostraron un valor promedio cuatro veces mayor a la concentración dispuesta en los cuerpos receptores, no obstante, esta diferencia no es significativa desde el punto de vista regulatorio, puesto que no se encontró ningún valor violatorio de dicho parámetro en los vertidos al alcantarillado. En los efluentes dispuestos en cuerpos receptores solo se registró un reporte que supera el límite máximo según el RVRAR. Los SST oscilaron entre $<0.2-181 \mathrm{mg} / \mathrm{L}$ (Fig 6.e), la distribución de los datos no presentó diferencia significativa de acuerdo con el tipo de vertido $\left(\chi^{2}=0.5, \mathrm{p}>0.05\right)$, por lo tanto, los valores promedio para vertidos a cuerpo receptor y alcantarillado son muy similares e incluso menores a la mitad del límite máximo del RVRAR; a pesar de lo anterior, se encontraron valores violatorios para la actividad de supermercado y locales comerciales que vierten a cuerpo receptor. Los sólidos sedimentables y suspendidos, en principio, son removidos en etapas de tratamiento primario y secundario, no obstante, puede existir material remanente en el efluente de salida, por lo que el control de estos parámetros es importante, debido a que este material contribuye significativamente al flujo de nitrógeno y fósforo de los cuerpos receptores, y es un factor que puede favorecer los procesos de eutrofización y la modificación de parámetros químicos y biológicos que juegan un rol importante en el equilibrio de los ecosistemas hídricos $(\mathrm{Ca}-$ rey y Migliaccio, 2009; Merbt et al., 2015).

El parámetro de SAAM osciló entre < 0.002-12.1 mg/L (Fig 6.f), con una distribución significativamente distinta de acuerdo con el tipo de vertido $\left(\chi^{2}=3.7, p<0.05\right)$, la concentración dispuesta en el alcantarillado fue aproximadamente 3 veces mayor que la dispuesta en cuerpos receptores; no obstante, los valores promedio son menores que el límite máximo establecido en el RVRAR. Se encontraron únicamente 2 reportes que superaban los $5 \mathrm{mg} / \mathrm{L}$. A pesar de lo anterior, el parámetro de SAAM como estimador de la carga orgánica aportada por sustancias surfactantes es importante que sea controlado en los efluentes de los PTAR's, ya que se han demostrado impactos en la biodiversidad acuática de los cuerpos receptores, debido a importantes efectos eco tóxicos de dichas sustancias (Rebello et al., 2014), además de biodegradabilidades cercanas a los 30 días (García et al., 2009). Las GyA oscilaron entre $<0.2-102 \mathrm{mg} / \mathrm{L}$ (Fig 6.g), no se encontraron diferencias significativas en la distribución de los datos de acuerdo con el tipo de vertido $\left(\chi^{2}=0.7, p>0.05\right)$, mientras que solo dos actividades (residencial y fabricación de dulces) presentaron valores superiores al límite máximo. A pesar de que las GyA provenientes de fuentes residenciales son mayoritariamente ácidos grasos de rápida biodegradabilidad (Willey 2001), estas sustancias propician la disminución del 
oxígeno disuelto de los cuerpos receptores; además, existe una proporción de GyA que pueden provenir de lubricantes y otros compuestos sintéticos que contienen compuestos aromáticos, hidrocarburos clorados e incluso metales pesados, lo cual incrementa el riesgo por ecotoxicidad para el cuerpo receptor (Diphare et al., 2013).

Los valores de DBO y DQO oscilaron entre $<0.1-139 \mathrm{mg} / \mathrm{L}$ y $<0.4-374 \mathrm{mg} / \mathrm{L}$ respectivamente (Fig 6.h y Fig 6.i), en ambos casos no existe diferencia significativa en la distribución de los datos de acuerdo con el tipo de vertido $\left(\chi^{2}=1.9\right.$ y $\left.0.6, p>0.05\right)$, tampoco se encontraron reportes con valores superiores al límite máximo del RVRAR. A pesar de lo anterior, es importante destacar que datos de Castro et al. (1996) muestran valores de caudal entre $0.84-68 \mathrm{~L} / \mathrm{s}$ para el río Bermúdez en una estación ubicada en el cantón San Pablo, esto sugiere que, al ser un receptor de bajo caudal, es más susceptible a respuestas negativas inmediatas derivadas de los vertidos de agua residual, con posibilidades de ocasionar niveles de oxígeno disuelto menores a valores críticos para el ecosistema acuático (Cotta et al., 2017).

En la Figura 7.a se observa que, del total de reportes operacionales presentados, la mayoría corresponde a la actividad residencial, tanto para los vertidos al alcantarillado sanitario como al cuerpo receptor; lo anterior es congruente con la Figura 6.a, ya que es la actividad que mayor caudal vierte, por
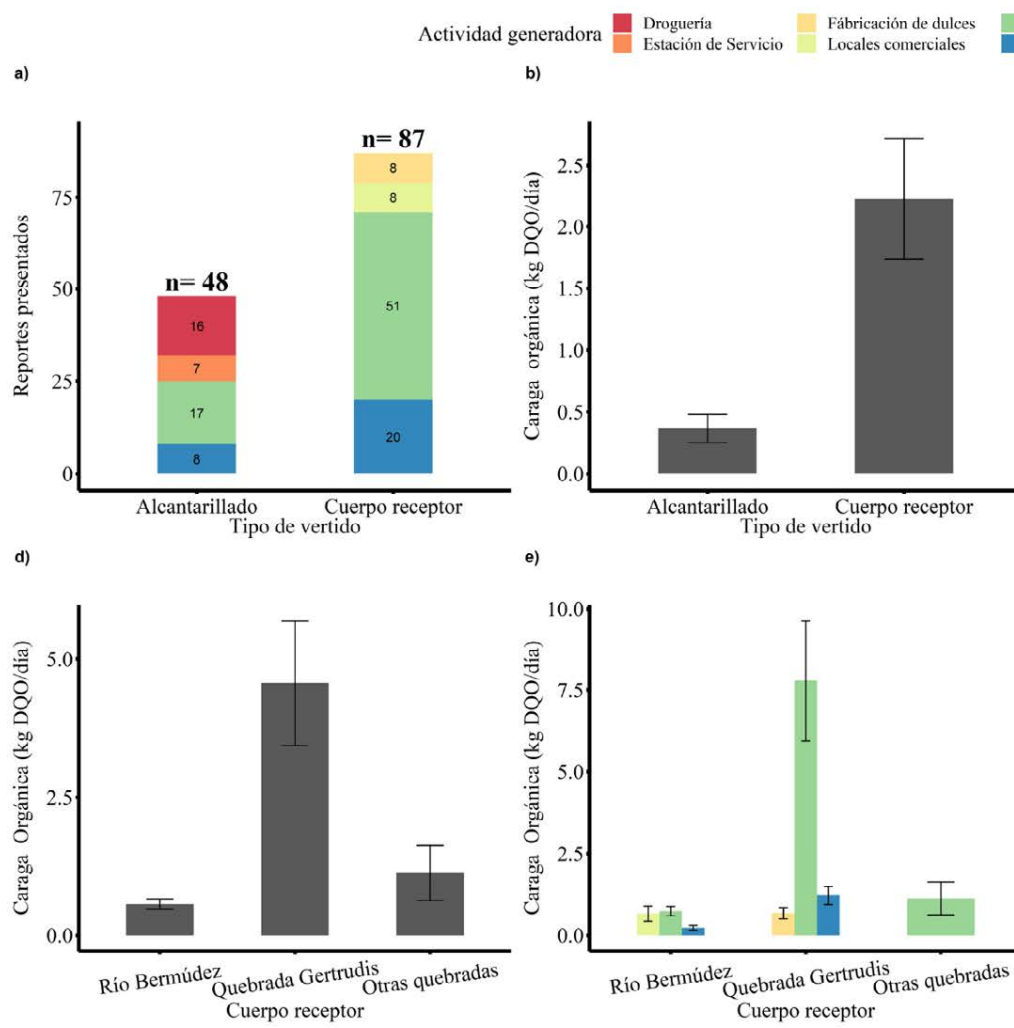

Residencial
Supermercado
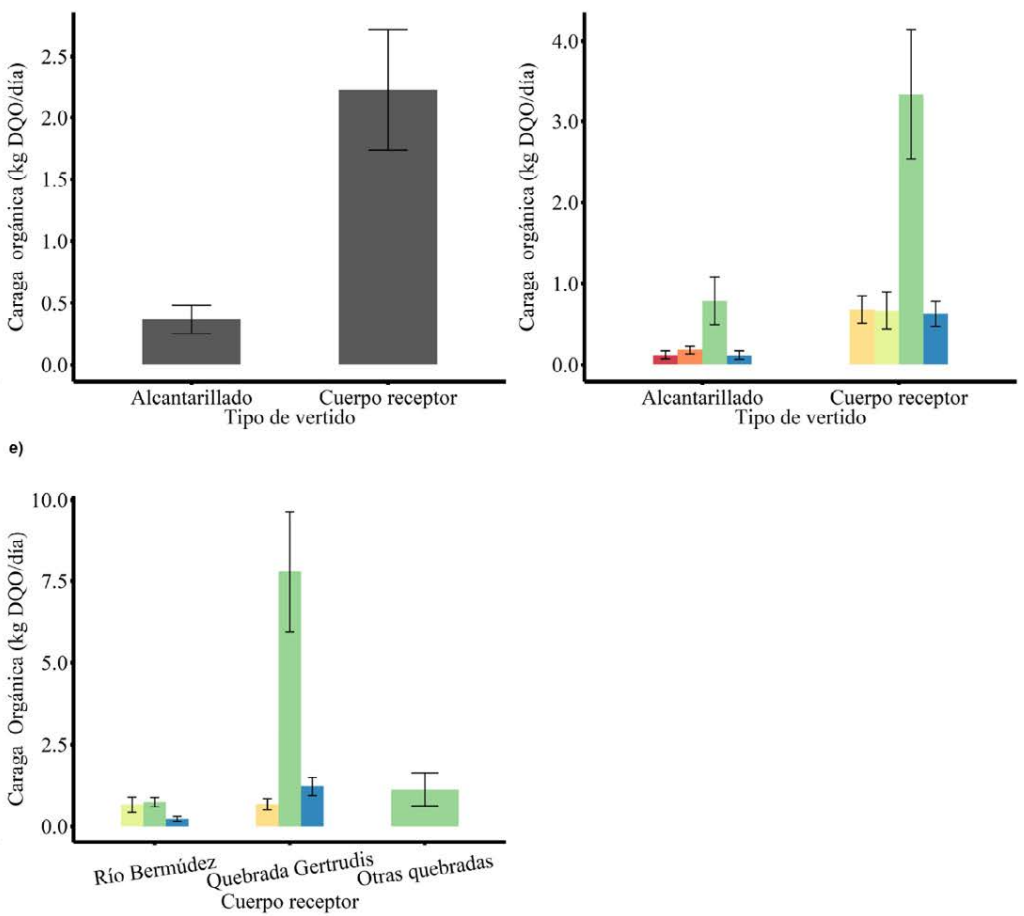

Figura 7. Distribución del número de reportes operacionales de aguas residuales y carga orgánica promedio vertida en el cantón San Pablo de acuerdo con el tipo de vertido y cuerpo receptor (nota: las barras representan el error estándar del promedio). Elaboración propia del estudio. 
lo que, según el RVRAR, la frecuencia de reporte operacional es mayor. También destaca que existen actividades que no realizan vertidos directos a los cuerpos receptores; empero, el cantón San Pablo actualmente no cuenta con un sistema de tratamiento centralizado de aguas municipales, por lo que eventualmente estos vertidos serán dispuestos en cuerpos receptores. $\mathrm{Al}$ respecto, destaca que la contribución de las actividades de estación de servicios y droguería podrían aportar cargas importantes de metales pesados o residuos de drogas que contribuyan a la carga de contaminantes emergentes en los sistemas acuáticos (Chon et al., 2012; Williams et al., 2019).

En aras de generar un indicador ambiental relacionado con la carga de materia orgánica que se genera en las PTAR's del cantón San Pablo, se propone un indicador que expresa los kilogramos de DQO vertidos por día, en la Figura 7.b, se observa que el valor promedio de este indicador es mayor para los vertidos en cuerpos receptores en relación con los de alcantarillado ([2.22 \pm 0.49$] \mathrm{kg} \mathrm{DQO} /$ día y [0.37 \pm 0.11$]$ $\mathrm{kg} \mathrm{DQO} /$ día, respectivamente). Además, en la Figura 7.c se muestra que el valor promedio de carga orgánica vertida en cuerpo receptor por la actividad residencial es bastante mayor ([3.34 \pm 0.11$] \mathrm{kg} \mathrm{DQO} /$ día) en relación con las actividades de fabricación de dulces, locales comerciales y supermercados $([0.68 \pm 0.17] \mathrm{kg} \mathrm{DQO} / \mathrm{dí} a,[0.67 \pm$ $0.23] \mathrm{kg} \mathrm{DQO} /$ día y $[0.63 \pm 0.16] \mathrm{kg} \mathrm{DQO} /$ día, respectivamente). En el caso de la carga vertida en alcantarillado, la actividad residencial también es significativamente mayor en relación con las demás actividades; sin embargo, es 4.3 veces menor en relación con los vertidos a cuerpo receptor de esta misma actividad ([0.78 \pm 0.29$] \mathrm{kg} \mathrm{DQO} /$ día). Analizando únicamente los vertidos a cuerpos receptores, destaca en la Figura 7.d que el componente hídrico del cantón San Pablo que mayor cantidad de carga orgánica recibe por día es la Quebrada Gertrudis, con un valor promedio de $(4.6 \pm 1.1) \mathrm{kg}$ DQO/ día, además, en la Figura 7.e, resalta nuevamente que es la actividad residencial la que mayor cantidad de carga genera con un valor promedio $(7.8 \pm 1.8) \mathrm{kg} \mathrm{DQO} /$ día, $6.5 \mathrm{y}$ 11.5 veces más que las otras actividades que poseen vertidos sobre este cuerpo receptor $([1.22 \pm 0.27] \mathrm{kg} \mathrm{DQO} /$ día y $[0.68 \pm 0.217]$ $\mathrm{kg}$ DQO/día para supermercados y fabricación de dulces, respectivamente).

Es importante contrastar los resultados obtenidos en relación con el cumplimiento de la mayoría de los parámetros de vertido y la cantidad de carga orgánica vertida, pues a pesar de que los reportes operacionales muestran un alto cumplimiento de los valores normativos, se evidencia que las cargas orgánicas vertidas pueden ser significativas en cuanto a la capacidad de autodepuración del cuerpo receptor (Gavrilescu et al., 2020). Lo anterior es de gran importancia puesto que, hasta nuestro entendimiento, no existe una evaluación integral de la capacidad receptora de los sistemas acuáticos, por lo que analizar únicamente el cumplimiento regulatorio puede ser algo superficial. Además, existe evidencia de que el río Bermúdez actualmente posee niveles de contaminación moderados y que este dato se encuentra relacionado con el aumento en la contribuciones de origen antropogénico, las cuales presentaron una tasa de crecimiento del $8.7 \%$ durante el período 2006-2010 (Herrera-Murillo et al., 2013); por lo que es imperativo generar acciones para mantener un indicador estable y ecológicamente equilibrado de la carga orgánica vertida en cuerpos receptores, para no afectar las diversas funciones ecosistémicas que 
brindan los ríos y, de esta forma, contribuir al mejoramiento ambiental, social y económico del cantón (Gavrilescu et al., 2020, Sibanda et al., 2015).

\section{Conclusiones}

De la percepción socioambiental es posible deducir que parte importante de la población sondeada se encuentra muy satisfecha en relación con la calidad del servicio de agua que recibe; pero, a su vez, se evidencia un desinterés relacionado con el saneamiento de las aguas, puesto que se observó falta de mantenimiento a los sistemas con los que cuenta el hogar (82\% tanque séptico), además del vertido de aguas grises al alcantarillado pluvial, las cuales desembocan en los cuerpos de agua superficial del cantón. Lo anterior representa un aspecto importante que puede incidir sobre la contaminación del recurso hídrico, por lo que, a pesar de existir una buena disposición por parte de las personas encuestadas para participar en las mejoras de saneamiento del recurso hídrico, es necesaria la implementación de estrategias con enfoque participativo, en aras de promover una mayor identidad cultural del agua.

Otro aspecto de alta incidencia para la contaminación del recurso lo representan los cambios en el uso de suelo y las fuentes directas e indirectas de contaminación, ya que en término de dos décadas, el cambio de uso de suelo fue bastante significativo. Se aumentó el área destinada a zonas urbanas y para cosecha de café; esto, con una importante disminución del área boscosa y de pastos, lo cual influye no solo en las características biofísicas del recurso hídrico, sino también en sus funciones ecosistémicas.

Actualmente, esta gran extensión de área urbana (49\% del área total) permite el desarrollo de actividades que pueden ser consideradas fuentes potenciales de contaminación al recurso hídrico. Se identificaron más de 193 patentes comerciales relacionadas con actividades de alta probabilidad para generar aguas residuales con impacto indirecto sobre el recurso hídrico de la zona en estudio.

Aunado a lo anterior, en el cantón se encuentran más de 18 fuentes de vertido directo de aguas residuales hacia cuerpos receptores, provenientes de diversas actividades productivas; en términos generales, existe un alto cumplimento con los parámetros establecidos en el RVRAR; sin embargo, se identificaron algunos valores violatorios para parámetros como S. Sed, SAAM y GyA; además, algunas de las actividades no realizan vertidos directos al cuerpo receptor, no obstante, la zona no cuenta con sistema de alcantarillado y tratamiento final, por lo que el sumidero de estos vertidos son los principales ríos de la zona, que reciben cargas altas en metales pesados y residuos de drogas, sobre todo de estaciones de servicio, salones de belleza y droguerías.

Debido a la alta densidad poblacional, el sector residencial es el principal contribuyente de los vertidos a cuerpos receptores y alcantarillado, por lo que dicha actividad puede estar generando un gran impacto, debido a la cantidad neta diaria vertida, principalmente sobre la Quebrada Gertrudis, ya que es el cuerpo receptor que más carga orgánica recibe.

Es recomendable realizar un análisis exhaustivo que permita evaluar la capacidad de depuración del cuerpo receptor. Además, un estudio diagnóstico del estado de los cuerpos receptores en general, que permitan evaluar la calidad del agua superficial; también, la implementación de sistemas de alcantarillado y drenaje, así como sistemas 
de tratamiento de las aguas residuales, que permitan, a los cuerpos de agua, una adecuada recuperación.

\section{Reconocimientos}

Este trabajo fue elaborado en el marco del proyecto de investigación de la Vicerrectoría de Investigación de la Universidad Nacional de Costa Rica: "Participación en los procesos de gestión ambiental del cantón San Pablo en la provincia de Heredia mediante la generación de indicadores relacionados con la condición de la red hídrica de la zona.", código SIA 0244-17. Se agradece a los sujetos participantes, colaboradores y estudiantes asistentes del proyecto, quienes en alguna medida aportaron en las giras de campo, en la interpretación de resultados, entre otros. Se agradece también al señor David González, gestor ambiental de la Municipalidad de San Pablo, por el apoyo brindado a través del proceso y a las estudiantes Jennifer Varela Carballo y Érika Bermúdez Méndez, por su colaboración en el procesamiento de los insumos geográficos.

\section{Conflicto de intereses}

Los autores declaran no tener conflicto de interés.

\section{Declaración de contribución de los autores}

El porcentaje total de contribución para la conceptualización, preparación y corrección de este artículo fue equitativo (16,7 $\%$ cada uno) entre todos los coautores.

\section{Declaración de disponibilidad de datos}

Los datos que respaldan los resultados de este estudio serán puestos a disposición por el autor correspondiente R.S-G, previa solicitud razonable.

\section{Referencias}

Barrenha, P. I. I., Tanaka, M. O., Hanai, F. Y., Pantano, G., Moraes, G. H., Xavier, C., \& Mozeto, A. A. (2018). Multivariate analyses of the effect of an urban wastewater treatment plant on spatial and temporal variation of water quality and nutrient distribution of a tropical mid-order river. Environmental Monitoring and Assessment, 190(1). https://doi. org/10.1007/s10661-017-6386-4

Blair, R. C., Higgins, J. J., Karniski, W., \& Kromrey, J. D. (1994). Multivariate Behavioral A Study of Multivariate Permutation Tests Which May Replace Hotelling' s T2 Test in Prescribed Circumstances. Multivariate Behavioral Research, 29(2), 141-163. doi: https:// doi.org/10.1207/s15327906mbr2902 2

Brenes, G. C. (2007). Evaluación y clasificación preliminar de la calidad del agua de la cuenca del río Tárcoles y el Reventazón. Revista Tecnología En Marcha, 20(2). https://revistas.tec. ac.cr/index.php/tec_marcha/article/view/46

Calvo-Brenes, G., \& Mora-Molina, J. (2012). Análisis de la calidad de varios cuerpos de agua superficiales en la GAM y la Península de Osa utilizando el índice holandés. Revista Tecnología En Marcha, 25(5). https://doi. org/10.18845/tm.v25i5.471

Carey, R. O., \& Migliaccio, K. W. (2009). Contribution of wastewater treatment plant effluents to nutrient dynamics in aquatic systems. Environmental Management, 44(2), 205-217. https://doi.org/10.1007/s00267-009-9309-5

Castillo, G. R. \& Saénz, E. (2020). Ríos Limpios: Estrategia Nacional para la recuperación de cuencas urbanas 2020-2030. Costa Rica: Un esfuerzo país. http://www.da.go.cr/wp-content/uploads/2020/02/Estrategia-Nacional-Rios-Limpios_Recuperacion-de-Cuencas-Urbanas-2020-2030.pdf 
Castro, L., Fraile, J., \& Reynolds, J. (1996). Conductividad, oxígeno disuelto, $\mathrm{pH}$ y temperatura en el rio Bermúdez (Costa Rica) y su relación con el uso del suelo en la cuenca. Uniciencia, 13, 27-34.

Chon, H. S., Ohandja, D. G., \& Voulvoulis, N. (2012). Assessing the relative contribution of wastewater treatment plants to levels of metals in receiving waters for catchment management. Water, Air, and Soil Pollution, 223(7), 3987-4006. https://doi.org/10.1007/s11270-012-1166-9

Cotta, A. J. B., Duboc, L. F., \& de Jesus, H. C. (2017). Impacts of urban wastewater and hydrogeochemistry of the São Mateus River, Espírito Santo, Brazil. Environmental Earth Sciences, 76(9). https://doi.org/10.1007/ s12665-017-6658-x

De Mello, K., Taniwaki, R. H., Paula, F. R. de, Valente, R. A., Randhir, T. O., Macedo, D. R. \& Hughes, R. M. (2020). Multiscale land use impacts on water quality: Assessment, planning, and future perspectives in Brazil. Journal of Environmental Management, 270. https://doi. org/10.1016/j.jenvman.2020.110879

Diphare, M. J., Pilusa, J., Muzenda, E., \& Mollagee, M. (2013). A Review of Waste Lubricating Grease Management. International Conference on Environment, Agriculture and Food Sciences, 131-134.

García, M. T., Campos, E., Marsal, A., \& Ribosa, I. (2009). Biodegradability and toxicity of sulphonate-based surfactants in aerobic and anaerobic aquatic environments. $\mathrm{Wa}$ ter Research, 43(2), 295-302. https://doi. org/10.1016/j.watres.2008.10.016

Gavrilescu, D.; Teodosiu, C., \& David, M. (2020). Environmental assessment of wastewater discharges at river basin level by means of waste absorption footprint. Sustainable Production and Consumption, 21, 33-46. https://doi.org/10.1016/j.spc.2019.10.006

Good, P. (2000). Permutation Test: A Practical Guide to Resampling Methods for Testing Hypotheses. P. Bickel, P. Diggle, S. Fienberg, K. Krickeberg, I. Olkin, N. Wermuth, \& S. Zeger (Eds.). Springer. doi: https://doi. org/10.1007/978-1-4757-3235-1

Gomes, P. I. A., \& Wai, O. W. H. (2020). Investigation of Long-Term River Water Quality Trends in Hong Kong to Identify Role of Urbanization, Seasons and Pollution Sources. Water, Air, and Soil Pollution, 231(7). https:// doi.org/10.1007/s11270-020-04753-1
Hidalgo García, M. del M. (2017). Las ciudades como objetivo de desarrollo sostenible. IEEE. Es, 3, 10 .

Hiremath, R. B., Balachandra, P., Kumar, B., Bansode, S. S., \& Murali, J. (2013). Indicator-based urban sustainability-A review. Energy for Sustainable Development, 17(6), 555-563. https://doi.org/10.1016/j. esd.2013.08.004.

Hernández-Moreno, S., Hernández-Moreno, J. A., \& Alcaraz-Vargas, B. (2018). Planeación inteligente de ciudades. Universidad Autónoma. http://hdl.handle.net/20.500.11799/94609

Hernando Echevarría, L., \& Orozco Montoya, R. (2015). Disponibilidad del recurso hídrico en la microcuenca del río Bermúdez. Región central de Costa Rica. Observatorio $\mathrm{Me}$ dioambiental, 18(0), 165-181. https://doi. org/10.5209/rev_obmd.2015.v18.51289

Herrera-Murillo, J., Rodríguez, S., Chaves-Villalobos, M., Herrera, É., \& Rojas, J. F. (2013). Variación temporal y espacial de la calidad de las aguas superficiales en la subcuenca del río Virilla (Costa Rica) entre 2006 y 2010. Tropical Journal of Environmental Sciences, 45(1), 51-62. https://doi.org/http://dx.doi. org/10.15359/rca.45-1.5

ICLEI. (2019). Resilient Cities, Thriving Cities: The Evolution of Urban Resilence. https:// iclei.org/en/publication/resilient-cities-thriving-cities-the-evolution-of-urban-resilience

La Gaceta. (2007). Reglamento de Vertido y Reuso de Aguas Residuales N. ${ }^{\circ}$ 33601-MINAE. Imprenta Nacional

Li, G. Y., Li, L. Z., \& Kong, M. (2020). Multiple-Scale Analysis of Water Quality Variations and Their Correlation with Land use in Highly Urbanized Taihu Basin, China. Bulletin of Environmental Contamination and Toxicology, 106, 218-224. https://doi. org/10.1007/s00128-020-02959-x

McCormick, K., Anderberg, S., Coenen, L., \& Neij, L. (2013). Advancing sustainable urban transformation. Journal of Cleaner Production, 50, 1-11. https://doi.org/10.1016/j. jclepro.2013.01.003

Meegoda, J. N., Li, B., Patel, K., \& Wang, L. B. (2018). A Review of the Processes, Parameters, and Optimization of Anaerobic Digestion. International Journal of environmental research and public health 15(10). https:// doi.org/10.3390/ijerph15102224 
Mena-Rivera, L., Vásquez-Bolaños, O., Gómez-Castro, C., Fonseca-Sánchez, A., Rodríguez-Rodríguez, A., \& Sánchez-Gutiérrez, R. (2018). Ecosystemic assessment of surface water quality in the Virilla River: Towards sanitation processes in Costa Rica. Water (Switzerland), 10(7), 1-17. https://doi.org/10.3390/w10070845

Mena-Rivera, L., Salgado-Silva, V., Benavides-Benavides, C., Coto-Campos, J. M., \& Swinscoe, T. H. A. (2017). Spatial and seasonal surface water quality assessment in a tropical urban catchment: Burío River, Costa Rica. Water (Switzerland), 9(8). https://doi. org/10.3390/w9080558

Merbt, S. N., Auguet, J. C., Blesa, A., Martí, E., \& Casamayor, E. O. (2015). Wastewater Treatment Plant Effluents Change Abundance and Composition of Ammonia-Oxidizing Microorganisms in Mediterranean Urban Stream Biofilms. Microbial Ecology, 69(1), 66-74. https://doi.org/10.1007/s00248-014-0464-8

Ministerio de Salud, MINAE \& AyA. (2016). Politica Nacional de Saneamiento de Aguas Residuales. Autor.

Mitchell, V. G. (2006). Applying integrated urban water management concepts: A review of Australian experience. Environmental Management, 37(5), 589-605. https://doi. org/10.1007/s00267-004-0252-1

Mohammadkhani, M., Masnavi, M., Rezaei Hariri, M. \& Mirmoghtadaee, M. (2020). Integrated Urban Water Management (IUWM) Framework Codification in Architectural and Urban Design: The Case of Hashtgerd Young City Project. Space Ontology International Journal, 9(4). 29-41. http://soij.qiau.ac.ir/article_680028.html

Municipalidad de Heredia. (2014). Caracterización general del cantón de San Pablo de Heredia. Autor.

Naidoo, S., \& Olaniran, A. O. (2013). Treated wastewater effluent as a source of microbial pollution of surface water resources. International Journal of Environmental Research and Public Health, 11(1), 249-270. https://doi. org/10.3390/ijerph110100249

Okoh, A. I., Sibanda, T., \& Gusha, S. S. (2010). Inadequately treated wastewater as a source of human enteric viruses in the environment. International Journal of Environmental Research and Public Health, 7(6), 2620-2637. https://doi.org/10.3390/ijerph7062620
Organización Mundial de la Salud. (2021). Saneamiento. Sitio Web. https://www.who.int/ topics/sanitation/es/

Peto, R., \& Peto, J. (1972). Asymptotically Efficient Rank Invariant Test Procedures. Journal of the Royal Statistical Society, 135(2), 185207. https://doi.org/10.2307/2344317

Prentice, R. L. (1978). Linear rank tests with right censored data. Biometrika, 65(1), 167-169. https://doi.org/10.2307/2335292

Rebello, S., Asok, A. K., Mundayoor, S. \& Jisha, M. S. (2014). Surfactants: Toxicity, remediation and green surfactants. Environmental Chemistry Letters, 12(2), 275-287. https://doi. org/10.1007/s10311-014-0466-2

Rosales-Escalante, E. (2016). Tanques sépticos. Conceptos teóricos base y aplicaciones. Editorial Tecnológica de Costa Rica.

Sánchez-Gutiérrez, R., \& Villalobos-González, W. (2020). Canon ambiental por vertidos en Costa Rica como instrumento económico en la gestión de aguas residuales: Un enfoque metodológico y de análisis de la situación actual. Repertorio Científico, 22(1), 38-49. https://doi.org/2215-565

Sánchez-Gutiérrez, R., \& Gómez-Castro, C. (2021). Acercamiento a los procesos de modelación de la calidad del agua en una subcuenca. Caso del río Virilla, Costa Rica. Uniciencia, 35(1), 71-89. https://doi.org/10.15359/ru.35-1.5

Sibanda, T., Selvarajan, R., \& Tekere, M. (2015). Urban effluent discharges as causes of public and environmental health concerns in South Africa's aquatic milieu. Environmental Science and Pollution Research, 22(23), 18301-18317. https://doi.org/10.1007/s11356-015-5416-4

Song, Y., Song, X., Shao, G., \& Hu, T. (2020). Effects of Land Use on Stream Water Quality in the Rapidly Urbanized Areas: A Multiscale Analysis. Water (Switzerland), 12(1123). https://doi.org/doi:10.3390/w12041123

Verma, P., \& Raghubanshi, A. S. (2018). Urban sustainability indicators: Challenges and opportunities. Ecological Indicators, 93, 282-291. https://doi.org/10.1016/j.ecolind.2018.05.007

Wakelin, S. A., Colloff, M. J., \& Kookana, R. S. (2008). Effect of wastewater treatment plant effluent on microbial function and community structure in the sediment of a freshwater stream with variable seasonal flow. Applied and Environmental Microbiology, 74(9), 2659-2668. https://doi.org/10.1128/ AEM.02348-07 
Willey, R. (2001). Fats, oils, and greases: The minimization and treatment of wastewaters generated from oil refining and margarine production. Ecotoxicology and Environmental Safety, 50(2), 127-133. https://doi. org/10.1006/eesa.2001.2081
Williams, M., Kookana, R. S., Mehta, A., Yadav, S. K., Tailor, B. L., \& Maheshwari, B. (2019). Emerging contaminants in a river receiving untreated wastewater from an Indian urban centre. Science of the Total Environment, 647, 1256-1265. https://doi.org/10.1016/j. scitotenv.2018.08.084

\section{(c) (i) $(5)$

Aspectos del contexto socioambiental que inciden en la contaminación del recurso hídrico en un cantón urbano (Rolando Sánchez-Gutiérrez, Carolina Alfaro-Chinchilla, Kimberly Ledezma-Zamora, Ligia Hernando-Echeverría, Carmen Mora-Aparicio, Roy Pérez-Salazar) Uniciencia is protected by Attribution-NonCommercial-NoDerivs 3.0 Unported (CC BY-NC-ND 3.0) 